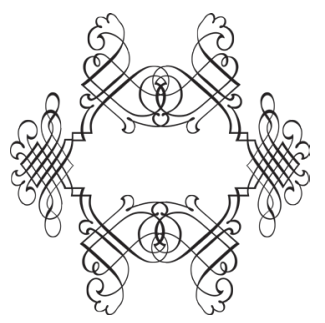

\title{
Розділ 1.
}

Сінергетичні сқладники творчого прогресу

УДК 7.012.23:338.49

DOI 10.34064/khnum2-2101

Гула Є. П.

ORCID 0000-0002-3795-5463

Осадча А. М.

ORCID 0000-0002-1213-0705

Київський національний університет технологій та дизайну; 01011, вул. Немировича-Данченка, 2, м. Київ, Україна

\section{Особливості впливу дизайну на прогрес людства}

\section{АНОТАЦІЯ — Гула Є. П., Осадча А. М. Особливості впливу ди-} зайну на прогрес людства. — У межах мистецтвознавчого дискурсу розглянуті особливості впливу дизайнерських розробок та концепцій на прогрес людства. Дослідники неоднозначно оцінюють це явище, тривають дискусії й пропонуються різні думки щодо впливу дизайну на технологічний і культурний прогрес людського суспільства. Метою статті є систематизація та узагальнення існуючих наукових поглядів на роль дизайну в суспільному прогресі. Дослідження залучає широкий теоретико-методологічний інструментарій - теорії дизайну, мистецтво- й культурознавства, соціальної психології, естетики та ін. Зіставлені визначення дизайну в працях ряду вітчизняних і зарубіжних науковців у контексті його культуротворчого впливу. Здійснений аналіз дизайну в його зв'язках із художньою творчістю. Визначені 
складові сучасного дизайнерського мистецтва. Встановлено, що прогрес людства значною мірою зумовлений позитивним впливом дизайнерських розробок і технологій, а дизайнерське проєктування є способом гармонізації життя людини в сучасному просторі, подолання розриву між технічною цивілізацією та духовною культурою. Новою прогресивною функцією дизайну в світовій культурі XXI ст. стало забезпечення єдності навколишнього природного середовища й людини на основі новітніх технологій та взаємодії й синтезу мистецтв. - Ключові слова: дизайн, дизайнери, мистецтво, концеепиіï, розробки, людство, проєкт, проєктування, технології, прогрес.

АННОТАЦИЯ — Гула Е. П., Осадчая А. Н. Особенности влияния дизайна на прогресс человечества. - В рамках искусствоведческого дискурса рассмотрены особенности влияния дизайнерских разработок и концепций на прогресс человечества. Исследователи неоднозначно оценивают это явление, длятся дискуссии и предлагаются разные мнения относительно влияния дизайна на технологический и культурный прогресс человеческого общества. Цель статьи - систематизация и обобщение существующих научных взглядов на роль дизайна в общественном прогрессе. Исследование привлекает широкий теоретико-методологический инструментарий - теории дизайна, искусствоведения, культурологии, социальной психологии, эстетики и др. Сопоставлены определения дизайна в работах ряда отечественных и зарубежных авторов в контексте его культуротворческого влияния. Осуществлен анализ дизайна в его связи с художественным творчеством. Определены составляющие современного дизайнерского искусства. Установлено, что прогресс человечества в значительной мере обусловлен позитивным влиянием дизайнерских разработок и технологий, а дизайнерское проектирование является способом гармонизации жизни человека в современном пространстве, преодоления разрыва между технической цивилизацией и духовной культурой. Новой прогрессивной функцией дизайна в мировой культуре XXI в. стало обеспечение единства окружающей природной среды и человека на основе новейших технологий и взаимодействия и синтеза искусств. К Ключевые слова: дизайн, дизайнеры, искусство, концепџии, разработки, человечество, проект, проектирование, технологии, прогресс. 
ABSTRACT - Hula Yevhen, Osadcha Alla. Features of the impact of design on the progress of humanity.

- Background. Within the framework of art-historical discourse, the peculiarities of the influence of design developments and concepts on progress of humanity are considered. Researchers offer ambiguous estimates of this phenomenon, discussions are lasting and different opinions on the issues of influence of design on technological and cultural progress of human society are putting forward. The aim of the paper is to systematize and generalize scientific concepts about the design role in the society progress. Novelty of the research consisting in synthesis of information on features of development of design for the last years in various spheres of culture and social practice defines its practical significance: the Ukrainian educators and art critics can consider the information contained in the article useful to develop new strategy of training in bases of design to non-specialist students.

Methodology. Major publications and monographs on the subject have been reviewed. It has been found that terminological judgment of design began with the middle of the XX century, first, within postmodern paradigm. The design as a component of culture correlates with cultural and art traditions, philosophy, ecology and other areas of public and humanitarian knowledge. Hence, the study of the role of design in ensuring progress provides for the wide use of theoretical and methodological tools not only of design theory, but also of other disciplines: art history, cultural studies, social psychology, aesthetics, ecology, etc. The design is considered both as universal and as a national phenomenon. The definitions of design in the works of a number of domestic and foreign authors in the context of its cultural-creative influence are compared. The analysis of design in its connection with artistic creativity is carried out. The components of contemporary design art are determined, the characteristic to the newest manifestations of design is given.

Results. The design represents the hierarchical structure expressed by means of a material, space and balance of proportions, contrasts, repetitions (in ornaments, etc.), scale and a form, a size, a color and density, texture and weight, and other. It is possible to consider culture of design as the huge multilayered text, which is written down by different ways in different spheres of culture and art. However the dilemma "art or production" in the sphere of design is inevitable.

Design is directly involved in technical progress in material culture and uses the art of planning, invention, modeling as a method, also introducing new 
object forms (see, for example, Vershinin \& Melentyev, 2005: 1001). The design role in culture is connected with creation of esthetically perfect fine environment. At the same time, it is differentiated essentially depending on the region of the world. So, design creativity is reasonably considered a manifestation of project activities and project culture of the 20th century. However, the progressive function of design at the beginning of the 21st century is that design is becoming a way to bridge the gap between technical civilization and spiritual culture, and design projecting is becoming a way of harmonizing human life in a modern environment. The importance of design for the progress of humankind is clearly demonstrated by the modern ecological direction, one of the components of the international movement of "green" design, namely, "environmental" design. This concept implies the creation of products that are compatible with the environment, the reduction and complete elimination of the negative impact on nature through the use of alternative resources and energy, as well as non-toxic materials. Ideally, the design should be in line with the "3R" ecological principle: reduce, reuse, and recycle.

The value of design for progress in art can be understood, having only tracked integration of painting, architecture, industrial and graphic design and having seen what the role in tangled process of creation of design is played by contents and a form, which also are the expression of the thought, the point of view and social responsibility of the designers. It is also important to emphasize the role of the designer's profession, because for many artists design and art is a cultural mission, where life and work are inseparable.

Judgments of design in art are formed, proceeding from two types of estimates: symbolical, or associative (external), and formal (internal). Symbolical estimates are mostly subjective and have no relation to design or art per se, being most often based on a habit, rumors, others thought, personal factors, prejudices, misunderstanding, that is on social, psychological, political, financial and even religious factors. Internal assessments concern an esthetics and actually design (appearance of the work of art, its visual quality) regardless of what it personifies. If external estimates belong to contents, then internal - to beauty. The latter is difficult to measure it and here such factors as talent, erudition, taste, susceptibility, experience and visual feeling matter. When determining a role of design in art, it is also necessary to remember that the principles of laconicism, laws of color, a rhythm and even plot equally work in any material, these fundamentals exist out of time, space, the state, school or style. 
To resume, human progress is largely driven by the positive influences of design concepts. Summarizing the views of Ukrainian and foreign researchers, it can be argued that design as a type of purposeful creative activity of mankind contributes to progress, since: 1) provides support for the development of civilization by creating new and improving known man-made objects; 2) creates an optimal human environment in order to achieve maximum comfort of his existence; 3) contributes to the formation of creative personality traits, its purposeful activity, which is one of the main social tasks. Design acts as an universal phenomenon, which covers different spheres of human activity, being, at the same time, the factor of socio-cultural communication and the basis for personality realization. As the socio-cultural phenomenon, it correlates with understanding of the person as source of intrinsic forces acting like the harmony catalyst in space. - Key words: design, designers, art, concepts, developments, humankind, project, design, technologies, progress.

Постановка проблеми. Прогрес у розумінні винайдення нових, оригінальних рішень у ході творчої діяльності людини продовжувався кілька десятків тисяч років, що зрештою й визначило сьогоднішній рівень людської цивілізації. Прогресування у дизайнерській справі спостерігалося в більше ніж два останні сторіччя, коли почався розвиток промислових мануфактур, а на зміну ремісничому дизайну (один майстер) прийшов «індустріальний дизайн», який передбачає використання високопродуктивних машин і автоматів. Створення нових матеріалів потребує вдосконалення технології їх обробки, сприяє виникненню нових технологічних процесів, які характеризуються більш широкими можливостями впливу на матеріал. У цьому полягає сутність технічного прогресу. Позитивні зміни у матеріально-технологічній базі, в свою чергу, забезпечують поступальний розвиток дизайну, що позначається на прогресі практично у всіх сферах людської діяльності (Голубятников, 2011: 15).

Віддаючи належне вже проведеним дослідженням, що тривають на Заході орієнтовно з 1950 років, а в Україні з 1991 року, в тому числі на базі провідних профільних закладів вищої освіти, слід вказати на 
потребу в узагальненні й систематизації інформації щодо особливостей ролі дизайну в культурному прогресі. Дослідниками надаються неоднозначні оцінки цього явища, тривають дискусії й пропонуються різні погляди щодо основних виявів впливу дизайну на технологічний і культурний прогрес людського суспільства. Отже, об'сктом даного дослідження $є$ дизайн, а його предметом - вплив дизайну на цивілізаційний прогрес людства. Метою даної статті $є$ систематизація та узагальнення наукових поглядів на роль дизайну в суспільному прогресі.

Науковий апарат дизайну був сформований десятиліття тому плеядою талановитих зарубіжних i вітчизняних дослідників. Термінологічне осмислення дизайну відбувалося із середини ХХ ст., насамперед, у рамках постмодерної парадигми. Вивчення ролі дизайну в забезпеченні прогресу передбачає широке залучення теоретико-методологічного інструментарію не лише теорії дизайну, але й інших дисциплін: мистецтво- й культурознавства, соціальної психології, естетики та ін. Тобто, дизайн як складова культури корелює 3 мистецтвом, філософією, екологією та іншими галузями суспільного й гуманітарного знання; спостерігаються тісні міждисциплінарні взасмини в межах означеної проблеми, і1ї зв'язок із важливими завданнями ряду наукових дисциплін.

Виклад основного матеріалу. Фактично, дизайн являє собою ієрархічну структуру, виражену за допомогою простору, форми, розміру, фактури / текстури матеріалу, щільності та ваги, кольору, орнаментів; контрасту, повторень, масштабу, балансу пропорцій. Культуру дизайну можна розглядати як величезний багатошаровий текст, який записаний у різний спосіб в різних сферах культури та мистецтва. Однак дилема «мистецтво або виробництво» у сфері дизайну неминуча.

Відповідно до одного із найбільш розповсюджених визначень, дизайн - це «творча діяльність людини, спрямована на розробку й створення об'єктів матеріальної й духовної культури, що формують комфортне середовище існування людини» (Голубятников, 2011: 11). Ще 1950 р. західний дослідник Е. Кауфман зазначав: «Гарний дизайн - це ретельне поєднання форми й функції, розуміння загальнолюдських цінностей, яке реалізується в промисловому виробництві для потреб демократичного суспільства» (як цит. Рэнд, 2013: 38). 
У 1960 роках викладачі Англійського Королівського коледжу мистецтв визначили дизайн як «сукупний досвід матеріальної культури й сукупний масив знань, навичок і цінностей, втілений у мистецтві планування, винаходу, формоутворення й виконання» (Вершинин \& Мелентьев, 2005: 1001). Звідси, британські педагоги також вперше висунули власну концепцію щодо значення дизайну в людському прогресі, яка містить такі положення:

- дизайн безпосередньо дотичний до технічного прогресу в матеріальній культурі й використовує в якості методу мистецтво планування, винаходу, формоутворення та виконання;

- дизайн має власні предмети, способи та методи репрезентації;

- основна задача дизайну - концептуалізація й втілення нових предметних форм;

- інструментарієм дизайну є мова моделювання, еквівалентна мові науки й гуманітарній мові (Вершинин \& Мелентьев, 2005: 1001).

У зарубіжних дослідженнях особливу увагу також приділено методології дизайну, зокрема, Г. Саймон у книзі «Науки штучно створеного» («The Sciences of the Artificial») (Simon, 1969: 67) актуалізує проблеми дизайну як такі, що є надто складними для вирішення, оскільки в той період не існувало жодної наукової методології у зазначеній сфері. Інші автори переконані, що проєктування (і виробництво) речей забезпечує особливий сегмент людської соціальної діяльності. Якщо теорія дизайну як методу художнього конструювання окремих промислових виробів виникає слідом за розвитком практики, а власне художнє конструювання, у сучасній його формі, складається до виникнення його теорії й обходиться без неї, то загальна теорія дизайну - теорія загального проєктування - має передувати додаванню цієї сфери до людської соціальної діяльності; вона виступає як основа iї побудови (Теоретические и методологические исследования в дизайне, 2004: 37).

Сфера дизайну як засіб прогресу в художньо-комунікативній системі розглядається Е. Глінтерніком, на думку якого, прогресивна роль дизайну полягає у тому, що він має спричиняти формування певних асоціацій і символічних образів. Автор переконаний, що перенос акцентів зі споживацьких характеристик на естетику то- 
вару сприяє прогресу, призводячи до необхідності пошуку таких дизайнерських рішень, які б вербалізували комунікативні смисли (Глинтерник, 2002: 55).

Значення дизайну для прогресу в сфері декоративно-прикладного й образотворчого мистецтва досліджені I. Кузнецовою, котра акцентує увагу на тому, що візуальне сприйняття дизайн-об'єктів змінюється 3 часом. 3 огляду на зазначене, на поточному етапі при створенні будь-якого виробу необхідно прогнозувати особливості його сприйняття. Саме тому, беручи за основу прогресивні технічні інновації, дизайнери мають також звертатися до національних традицій і технік декоративно-прикладного мистецтва тощо (Кузнецова, 2007: 97-111).

Приділяючи увагу проблемам середовища як центра існування художніх форм, синтезу та ідейно-естетичному наповненню останніх, К. Кондратьєва (2000) передбачає включення сукупності художньо-декоративних засобів, об'єктів кольорової графіки та пластики в міське середовище, а засобів театралізації, видовищності - в міський дизайн. Як вважає вчена, дизайн розкривається через арсенал монументально-декоративних форм і засобів формування художньо-емоційного потенціалу. «На думку ряду дизайнерів, предметний світ повинен стати носієм нової функції, яка визначила б соціальну поведінку людини в суспільстві...» (Кондратьева, 2000: 17). К. Кондратьєва також наголошує на тому, що середовищна складова дизайну виводить на перше місце розбудову засобами проєктування гармонійних стосунків людини з навколишнім світом. Тобто, екологічна складова архітектурної і дизайнерської практики актуалізує питання співіснування людини і природи. Головним показником такого співіснування виступає сприйняття індивідом себе як частини природи. Отже, природне середовище існування - це засіб ототожнення себе з цілим, розуміння себе як його частини. Відтак, дизайн починає виконувати функцію гармонійного поєднання духовних, творчих та інтелектуальних цінностей і виступає джерелом задоволення морально-етичних потреб (Кондратьева, 2000: 60).

У першій половині 2010 років вітчизняні науковці активно розглядали роль дизайну в окремих сферах мистецтва. Розвиток графічного дизайну в зв'язку із поширенням інформаційних, зокре- 
ма, комп'ютерних, технологій вивчає Л. Турчак (2011: 11). Прогрес у цій сфері засвідчує те, що, починаючи приблизно з 1990 років і до сих пір, художники-графіки освоюють нові техніки та комп'ютерні «ноу-хау». Дослідниця Н. Сбітнєва (2011) провела мистецтвознавчий аналіз проблем сучасного графічного дизайну та розглянула перспективи його подальшого розвитку. Автор наголошує на суттєвих змінах, що відбулись в традиційному дизайні: «Застосування нових сучасних технологій ... відкрило перед графічним дизайном необмежені можливості в плані створення і обробки зображення і шрифту ...» (Сбітнєва, 2011: 53). Можна погодитися з думкою автора щодо проблеми «засмічення» візуального простору та підвищення вимог комунікативного середовища до якості дизайну: «Це змушує фахівців шукати ефективніші засоби дії, нові форми подачі, розраховані на реципієнта, не готового прочитувати довгі (як вербальні, так і невербальні) візуальні тексти» (Сбітнєва, 2011: 54). Витоки цього Н. Сбітнєва вбачає в естетичній сутності постмодернізму: «...розмивання звичного стереотипу сприйняття, використання нонсенсу, цитат, алюзій, парафраз та інших подібних художніх прийомів сприяло появі у графічному дизайні початку XXI сторіччя антидизайнерського, “сміттєвого” підходу» (там само). Крім того, дослідниця актуалізує питання створення національного графічного мистецтва, що є головним вектором розвитку вітчизняного дизайну. Вона наголошує на важливості «пошуків елементів візуальної ідентифікації країни, які могли б гідно представляти імідж держави на міжнародній арені» (там само).

Зрештою, варто навести і визначення дизайну, зафіксоване у законодавстві нашої держави. У статті 1 Закону України «Про авторське право і суміжні права» $(1994: 13,64)$ твори художнього дизайну віднесені до творів образотворчого мистецтва. Виходячи з інших нормативно-правових актів України (та їхніх проєктів), дизайнерська творчість призначена для надання естетичних якостей товарам повсякденного вжитку, промисловій продукції та середовищу проживання людини (Рекомендації щодо забезпечення правомірності створення та використання творів дизайну, 2019).

Отже, дизайнерську творчість обгрунтовано вважають проявом проєктної діяльності й проєктної культури XX ст. Однак прогресив- 
на роль дизайну на початку XXI ст. - це спосіб подолання розриву між технічною цивілізацією та духовною культурою, а дизайнерське проєктування є способом гармонізації життя людини в сучасному середовищі.

Розглянемо значення дизайну для прогресу людства на прикладі ролі дизайну в екології. Саме екологічний трек має стати складовою міжнародного руху «зеленого» дизайну, а саме, «environmental», стосовно навколишнього середовища. Це поняття передбачає створення продукції, сумісної із навколишнім середовищем, зниження та повне усунення негативного впливу на природу за допомогою використання альтернативних ресурсів та енергій, а також нетоксичних матеріалів. В ідеалі дизайн має відповідати принципу екології «3R»: reduce reuse - recycle (зменшувати, повторно використовувати, переробляти). Для прикладу - в останні роки архітектори нашої країни почали застосовувати все більше сучасних еко-технологій для спорудження «зелених будинків». В таких будинках використовується менше опалення, електрики та комунікацій, циркуляція свіжого повітря більш ефективна за рахунок використання екологічно чистих будівельних матеріалів та покращених вентиляційних систем. Обслуговування таких будинків обходиться дешевше, а здоров'я працівників і мешканців лише міцніс. Яскравим прикладом такого еко-дизайну є вітчизняний проєкт «Bionic Hill», перший інноваційний парк в Україні, сучасне наукове містечко (BIONIC Hill. Innovation technopark, 2019). Проєкт одним 3 перших в Україні застосував світову екологічну систему сертифікації зеленого будівництва «The Leadership in Energy and Environmental Design» («LEED»), яка покликана мінімізувати вплив забудови на довкілля та здоров'я людей, що досягається шляхом зниження рівня споживання енергетичних та матеріальних ресурсів, підвищення якості будівель та комфорту їх внутрішнього середовища (там само).

Отже, новою прогресивною функцією дизайну в світовій культурі XXI ст. стало забезпечення цілісності та єдності навколишнього середовища і гармонійних стосунків з ним людини на грунті застосування новітніх технологій та взаємодії й синтезу мистецтв.

Значення дизайну для мистецького прогресу можна зрозуміти, лише простеживши поєднання живопису, архітектури, промислового 
і графічного дизайну і побачивши при цьому, яку роль у заплутаному процесі створення дизайнерського рішення відіграють зміст та форма, а також усвідомивши, що дизайн також виражає думку, точку зору й соціальну відповідальність його автора. Важливо також особливо наголосити на ролі професії дизайнера в мистецтві, адже для багатьох творців дизайн та мистецтво є культурною місією; при цьому життя і творчість нероздільні, а «символи віри» для них - це рівні поверхні, прості матеріали й стриманість виразних засобів.

Дизайн - це більше, ніж просто упорядкування й компонування візуального матеріалу. Дизайн - це привнесення цінностей і змістів, роз'яснення, перетворення, облагороджування, перебільшення, спрощення, освіта, переконання й, можливо, навіть розвага. Дизайн розширює наше сприйняття, множить наш досвід і загострює наш мистецький «зір», будучи при цьому продуктом почуття й розуму, ідеї, що виникла в голові дизайнера, що (як сподівається дизайнер) передасться глядачеві й спрацює в його свідомості (Рэнд, 2013: 14).

Судження про дизайн у мистецтві формуються, виходячи із двох типів оцінок: символічної, або асоціативної (зовнішньої), і формальної (внутрішньої). Символічні оцінки значною мірою є суб’єктивними й жодного відношення не мають до дизайну або мистецтва як такого, будучи найчастіше засновані на звичці, слухах, чужій думці, особистих факторах, забобонах, непорозумінні, тобто на соціальних, психологічних, політичних, фінансових і навіть релігійних, факторах. Натомість, внутрішня оцінка стосується естетики й власне дизайну (зовнішній вигляд твору мистецтва, його візуальна якість) безвідносно до того, що воно персоніфікує. Якщо зовнішні оцінки відносяться до змісту, то внутрішні - до краси. Ї̈̈ складно виміряти, і тут значення мають такі фактори, як талант, ерудиція, смак, сприйнятливість, досвід і візуальне чуття. При визначенні ролі дизайну в мистецтві варто також пам'ятати, що принципи лаконізму й домірності, закони кольору, ритму й навіть сюжету однаково працюють у будь-якому матеріалі. Ці об’ єктивні закономірності існують поза часом, простором, державами, школою або стилем.

Загалом же в епоху тотальної глобалізації розширюються підходи до розуміння дизайну, оскільки змінюється сприйняття людини, яке 
стає більш технологізованим. Тому в сучасному дизайні, крім традиційних напрямів - промислового й графічного дизайну - можна виділити інші виміри - постмодерністський, деконструктивістський, нелінійний і т. п. Феномен дизайну є універсальним, він охоплює різні сфери людської діяльності, виступаючи при цьому чинником соціокультурної комунікації та основою й виміром особистості та її сприйняття. Як соціокультурне явище, дизайн корелює із розумінням людини як джерела сутнісних сил, що виступають каталізатором гармонії у просторі.

Підсумки дослідження. Отже, прогрес людства значною мірою зумовлений позитивним впливом дизайнерських розробок і концепцій. Узагальнюючи погляди українських і зарубіжних дослідників, можна стверджувати, що, загалом, дизайн як вид цілеспрямованої творчої діяльності людства сприяє прогресу, оскільки: 1) забезпечує підтримку розвитку цивілізації шляхом створення нових і удосконалення відомих рукотворних об'єктів; 2) створює оптимальне середовище проживання людини з метою досягнення максимальної комфортності іiі існування; 3) сприяє формуванню творчих рис особистості, їі цілеспрямованої діяльності, що є одним 3 головних соціальних завдань.

Забезпечуючи власну прогресивну роль, в останній третині XX ст. дизайн перетворився у глобальне явище постіндустріального світу, що охопило нові сфері проєктної практики. Наразі питання місця дизайну в технологічному і культурному прогресі розглядається за двома напрямками: гуманізації (розширення антропологічних обріїв дизайну) та гуманітаризації (зростання інтересу до проєктної культури, що спостерігається в усьому світі).

Тема місця і значення дизайну для прогресу суспільства, безсумнівно, має кілька перспективних напрямів дослідження, зокрема: a) прогнозування нових дизайнерських розробок і концепцій у коротко- (1-2 роки), середньо- (5-7 років) та довгостроковій перспективах (7-10 і більше років); б) аналіз співвідношення національних традицій та новаторства в сучасному дизайні; в) виявлення негативних тенденцій впливу дизайну на прогрес у розвитку людських спільнот. 


\section{ЛІТЕРАТУРА}

Закон України «Про авторське право і суміжні права» (1994). Відомості Верховної Ради України, 13, ст. 64.

BIONIC Hill. Innovation technopark. Retrieved 2019, March 17 from http:// bionic-hill.com

Reduce, Reuse, Recycle. Recycling Guide. Retrieved 2019, December 17 from www.recycling-guide.org.uk/rrr.html

Simon, Herbert A. (1969). The sciences of the artificial. The MIT Press. Cambridge; Mass.: M.I.T. Press, 130.

Вершинин, Г. В. \& Мелентьев, Е. А. (Сост.). (2005). Хрестоматия по дизайну. Тюмень: Институт дизайна, 1056.

Глинтерник, Э. М. (2002). Графический дизайн как художественно-коммуникативная система и средство рекламы. Санкт-Петербург: Петербургский институт печати, 136.

Голубятников, И. В. (Ред.). (2011). Дизайн. История, современность, перспективы. Москва: Мир энциклопедий Аванта+; Астрель, 224.

Кондратьева, К. А. (2000). Дизайн и экология культуры. Москва: МГХПУ им. Строганова, 105.

Кузнецова, I. О. (2007). До питання про моделювання динаміки візуального сприйняття об'єктів дизайну, декоративно-прикладного та образотворчого мистецтва. Геометричне та комп'ютерне моделювання, 19, 97-111.

Рекомендації щодо забезпечення правомірності створення та використання творів дизайну. Retrieved 2019, December 17 from https://www.me.gov.ua/ Documents/Detail?lang=uk-UA\&id=212dbe8f-ce7b-4728-a689-512bae0fb98 c\&title $=$ RekomendatsiiSchodoZabezpechenniaPravomirnostiStvorenniaTaVi koristanniaTvorivDizainu\&isSpecial=true

Рэнд, П. (2013). Дизайн: форма и хаос. (Пер. с англ. И. Форонова). Москва: Издательство Студии Артемия Лебедева, 244.

Сбітнєва, Н. Ф. (2011). Графічний дизайн України початку III тисячоліття: проблеми та перспективи розвитку. Вісник Харківської державної академії дизайну і мистейтв. Мистецтвознавство. Архитектура, 6, 52-55.

Теоретические и методологические исследования в дизайне. (2004). Москва: Издательство Школы культурной политики, 372. 
Турчак, Л. І. (2011). Еволюиія образотворчого мистеитва в незалежній Україні. (Автореф. дис. ... канд. мистецтвознавства). Київський національний університет культури і мистецтв. Київ, 16.

\section{REFERENCES}

Zakon Ukrainy «Pro avtorske pravo i sumizhni prava» [The Law of Ukraine "On Copyright and Related Rights"]. Vidomosti Verkhovnoi Rady Ukrainy [Bulletin of the High Soviet of Ukraine], 1994, 13, 64 [in Ukrainian].

BIONIC Hill. Innovation technopark. Retrieved 2019, March 17 from http:// bionic-hill.com

Glinternik, E. M. (2002). Graficheskiy dizayn kak khudozhestvennokommunikativnaya sistema $i$ sredstvo reklamy [Graphic Design as an Artistic Communication System and a Means of Advertising]. St. Petersburg: Peterburgskiy Institut Pechati, 136 [in Russian].

Golubyatnikov, I. V. (Ed.) (2011). Dizayn. Istoriya, sovremennost, perspektivy [Design. History, Modernity, Perspectives]. Moscow: Mir Entsiklopediy Avanta+; Astrel, 224 [in Russian].

Kondrateva, K. A. (2000). Dizayn i ekologiya kultury [Design and Ecology of Culture]. Moscow: MGKhPU imeni Stroganova, 105 [in Russian].

Kuznetsova, I. O. (2007). Do pytannia pro modeliuvannia dynamiky vizualnoho spryiniattia obiektiv dyzainu, dekoratyvno-prykladnoho ta obrazotvorchoho mystetstva [On Modeling the Dynamics of Visual Perception of Objects of Design, Decorative Applied and Fine Arts]. Heometrichne $i$ komputerne modeliuvannia [Geometric and Computer Modeling], 19, 97-111 [in Ukrainian].

Rand, P. (2013). Dizayn: forma i khaos [Design: Form and Chaos]. (Trans. from English by I. Foronov). Moscow: Izdatelstvo Studii Artemiya Lebedeva, 244 [in Russian].

Reduce, Reuse, Recycle. Recycling Guide. Retrieved 2019, December 17 from www.recycling-guide.org.uk/rrr.html

Rekomendatsii shchodo zabezpechennia pravomirnosti stvorennia ta vykorystannia tvoriv dyzainu [Recommendations for Ensuring the Legality of the Creation and Use of Design Works]. Retrieved 2019, December 17 from https://www.me.gov.ua/Documents/Detail?lang=uk-UA\&id=212dbe8fce7b-4728-a689-512bae0fb98c\&title=RekomendatsiiSchodoZabezpechen 
niaPravomirnostiStvorenniaTaVikoristanniaTvorivDizainu\&isSpecial=true [in Ukrainian].

Sbitnieva, N. F. (2011). Hrafichnyi dyzain Ukrainy pochatku III tysiacholittia: problemy ta perspektyvy rozvytku [Graphic Design of Ukraine at the Beginning of the Third Millennium: Problems and Prospects for Development]. Visnyk Kharkivskoi derzhavnoi akademii dyzainu i mystetstv. Mystetstvoznavstvo. Arkhitektura [Bulletin of the Kharkiv State Academy of Design and Arts. Art Studies. Architecture], 6, 52-55 [in Ukrainian].

Simon, Herbert A. (1969). The sciences of the artificial. The MIT Press. Cambridge; Mass.: M.I.T. Press, 130.

Teoreticheskie i metodologicheskie issledovaniya $v$ dizayne (2004). [Theoretical and Methodological Research in Design]. Moscow: Izdatelstvo Shkoly kulturnoy politiki, 372 [in Russian].

Turchak, L. I. (2011). Evoliutsiia obrazotvorchoho mystetstva v nezalezhnii Ukraini [The Evolution of Fine Art in Independent Ukraine]. (Extended abstract of Candidate's thesis). Kyiv National University of Culture and Arts. Kyiv, 16 [in Ukrainian].

Vershinin, G. V. \& Melentev, E. A. (Comp.) (2005). Hrestomatiya po dizaynu [Chrestomathy on Design]. Tyumen: Institut Dizayna, 1056 [in Russian].

Стаття надійшла до редакиії 17.02.2020 p. 